\title{
Co-occurrence Patterns in Carnivorans: Correspondence Between Morphological and Ecological Characteristics of an Assemblage of Carnivorans in Patagonia
}

\author{
Sonia Cristina Zapata • Miguel Delibes • \\ Alejandro Travaini • Diego Procopio
}

\begin{abstract}
We searched for correspondence between morphology and trophic habits in an assemblage of six species of coexisting carnivorans from Patagonia to confirm the predictive power of the study of the trophic morphology as an approach to the study of resource partitioning, which is often utilized in paleontological studies. The six species were assigned to four morphoguilds and to four trophic guilds, although the species composition of both spaces was only coincident during one of the two studied time periods. The most obvious explanation for this lack of correspondence is based on the assumption that species can change from one ecological guild to another, while their relative positions in the morphospace will be fixed. Therefore, the observed lack of correspondence could be searched in the context of differences between the ecological and evolutionary scales. Although morphological specialization toward some type of diet has been corroborated in our assemblage, the inference of interactions in ecological time among species from the past from its morphology must be considered with caution.
\end{abstract}

Keywords Ecological guilds · Trophic morphology ·

Ecomorphology $\cdot$ Carnivorans $\cdot$ Patagonia

\section{Introduction}

The Carnivora usually share a unique dental pattern characterized by four different functional areas: canines and incisors, used for display, defense, killing prey, and dismembering

S. C. Zapata $(\bowtie) \cdot$ A. Travaini $\cdot$ D. Procopio Centro de Investigaciones de Puerto Deseado, Universidad Nacional de la Patagonia Austral, CONICET, Avenida Prefectura Naval S/N, 9050 Puerto Deseado, Santa Cruz, Argentina e-mail: titinazapata@yahoo.com.ar

M. Delibes

Department of Conservation Biology, Estación Biológica de Doñana, CSIC, Américo Vespucio S/N, 41092 Sevilla, Spain carcasses; premolars, used as piercers or crushers; a pair of scissor-like carnassials, the last upper premolar $\left(\mathrm{PM}^{4}\right)$ and the first lower molar $\left(\mathrm{M}_{1}\right)$, adapted for cutting flesh; and the postcarnassial molars, devoted to grinding (Van Valkenburgh 1989). Carnivoran species include a great diversity of feeding habits, which are roughly reflected in the emphasis placed on some of these functional areas. For example, specialized flesh eaters like felids possess long, robust, and sharp canines, and carnassials shaped for meat slicing throughout their length, acting like a blade. On the other hand, some mustelids emphasize the grinding area of $\mathrm{M}_{1}$ (the talonid basin) and postcarnassial molars for breaking down hard foods like arthropods and plant materials (Ewer 1973; Van Valkenburgh 1989). Between those extremes, there is an array of feeding types manifested in a high dental diversity. Thus, it is possible to obtain information on probable diets and prey preferences by examining teeth and furthermore to establish a connection between morphology and ecology through diet (Van Valkenburgh 1989, 1995; Van Vankenburgh and Wayne 1994; Biknevicius and Van Valkenburgh 1996; Prevosti and Palmqvist 2001; Prevosti and Vizcaíno 2006; Figueirido and Soibelzon 2009; Prevosti and Martin 2013). An ecomorphological approach allows the study of the relationship between the functional design of organisms and the environment (Wainwright and Reilly 1994), based on the premise that morphological adaptations of individuals reflect their ecological relationships (Van Valkenburgh 1995). This approach has been applied in numerous studies of carnivorous mammal communities, both extinct and extant, including a wide range of body sizes (see Friscia et al. 2007). In paleontology, ecomorphological studies have identified guilds of extinct species or "paleoguilds" (Van Valkenburgh 1989; Prevosti and Vizcaíno 2006; García and Virgós 2007; Figueirido and Soibelzon 2009; Prevosti and Martin 2013). Unlike guilds of extant species, in which their members are generally identified on the basis of shared resources (Blondel 2003), members of paleoguilds have been identified for their morphological similitude (Van Valkenburgh 1988). In paleoguilds, assigning species to particular guilds assumes that 
these are potential competitors because they share a trait, for example their body weight. Furthermore, the similarities of their morphological characteristics would allow them to use the same resources in a similar way, and this is consistent with guild definition (species using resources similarly, sensu Root 1967).

The paleoguilds described on the basis of morphological characteristics of the species (morphoguilds) have been compared with morphoguilds of extant species (Hertel 1994; Van Valkenburgh 1988, 1995; Palmqvist et al. 1999; Prevosti and Martin in press) inferring resource partitioning and trophic diversity in different environments from the past and the present. However, the correspondence between guilds established from morphological and ecological patterns in extant species has rarely been contrasted. Making that correspondence, one might confirm the predictive power of the study of the trophic morphology as an approach to the study of resource partitioning (Ricklefs and Travis 1980; Wainwright and Reilly 1994; Biknevicius and Van Valkenburgh 1996).

Further, there is increasing evidence that co-occurring guilds of species frequently demonstrate greater morphological disparity than predicted from null expectations (Dayan and Simberloff 2005; Davies et al. 2007; Meloro 2011). According to these authors, one of the main goals of community ecology is to explain patterns of co-occurrence among species in relation to their morphological and ecological characteristics (Davies et al. 2007).

In this work, we carried out this comparison using as a model the trophic guilds and morphoguilds identified in our previous works from an assemblage of carnivorans from the northeastern of Santa Cruz Province, Argentinean Patagonia (Zapata et al. 2007, 2008). The assemblage consisted of six species: puma (Puma concolor), pampas cat (Leopardus colocolo), lesser grison (Galictis cuja), culpeo fox (Lycalopex culpaeus), grey fox (L. griseus), and Patagonian skunk (Conepatus humboldtii). Our objective was to evaluate if guilds identified through a detailed study in the field (trophic guilds, which respond to a pattern of resources in an ecological time) correspond to guilds identified through morphological characteristics of the species (morphoguilds, which represent a similar pattern but in an evolutionary time). As morphological traits were conformed in evolutionary time and feeding habits were adjusted in ecological time, we expected some disagreement between morphoguilds and current trophic guilds, showing the last ones more flexibility.

\section{Materials and Methods}

\section{Study Area}

The study area was located in the northeastern portion of Santa Cruz Province, Patagonia, southern Argentina, and belongs to the Deseado Department. It is a region of $11.000 \mathrm{~km}^{2}, 50$ to
$300 \mathrm{~m}$ above sea level, which includes a protected area: the Monumento Natural Bosques Petrificados (approx. $47^{\circ} 66^{\prime} \mathrm{S}$, $67^{\circ} 99 \mathrm{~W}$ ) and the surroundings of Puerto Deseado city $\left(47^{\circ} 47^{\prime} \mathrm{S} ; 65^{\circ} 49^{\prime} \mathrm{W}\right)$. It is typically a flat steppe covered by tussock grasses and dome shaped spindly shrubs, with low cover $(20 \%$ to $30 \%)$ interrupted by ravines and rocky outcrops. The weather corresponds to that of a desert biome, with rainfall and snowfall fluctuating between 110 and $150 \mathrm{~mm}$, concentrated during the winter time. We distinguished two climatic seasons: 1) A relative warm and dry season, between October and March, corresponding to spring and summer; in this period, highest temperatures are reached, no rainfall is registered, and winds are of great frequency and intensity. 2) A relative cold season, from April to September, corresponding to autumn, winter, and the start of spring; this season concentrates precipitation and achieves the lowest temperatures, with frequent frosts (León et al. 1998).

\section{Data Collection}

We present a brief description of the methodology used in a previous work (Zapata et al. 2008). Specimen crania were obtained from dead animals located in the study area (now in the collection of the Centro de Investigaciones de Puerto Deseado) and from the Museo Argentino de Ciencias Naturales Bernardino Rivadavia. All measured crania belonged to adult animals, as indicated by the closure of cranial sutures and tooth wear pattern (Zapata et al. 1995, 1997a, b). We did not discriminate between sexes in our morphological analysis due to the absence of sex data in most specimens. Finally, the sample consisted of 33 crania from Lycalopex culpaeus; 18 from $L$. griseus; seven from Puma concolor; six from Leopardus geoffroyi; seven from Galictis cuja; and 13 from Conepatus humboldtii.

The six carnivoran species were compared in terms of the similitude of their trophic apparatus, based on 16 measurements related with the shape and size of teeth and mandibles (Fig. 1; Zapata et al. 2008). Measurements were taken with digital calipers and selected from Ewer (1973), Emerson and Radinsky (1980), Radinsky (1981, 1985), Van Valkenburgh (1989, 1995), Van Valkenburgh and Koepfli (1993), Van Valkenburgh and Wayne (1994), and Biknevicius and Van Valkenburgh (1996). These raw measurements were then combined to form dental and mandibular ratios previously considered to be functionally significant in carnivorous taxa (above cited authors and Friscia et al. 2007; Appendix 1).

\section{Multivariate Description of Morphospaces}

When calculating ratios, the raw data were transformed into $\log _{10}$ in order to normalize the distribution of the variables and to produce normal multivariate distributions of the species in the morphospace (Ricklefs and Travis 
Fig. 1 Craniodental and mandibular measurements employed in this study. The picture corresponds to a grey fox (Lycalopex griseus): CSAP, maximum width of upper canine; CSLM, maximum length of upper canine; $\mathrm{LD}$, mandible dentary length; LTC, total length skull; M1IL, maximum length of M1 (lower molar); M1SA, maximum length of first upper molar; M1SL, maximum width of first upper molar; M2IL, maximum length of M2; MM, mandible angular process; MT, mandible coronoid process; P4SAP, maximum length of the upper carnassial; TAP, anteroposterior length of the talonid (lower carnassial grinding area); TRI, trigonid (lower carnassial blade length). From Zapata et al. (2008)
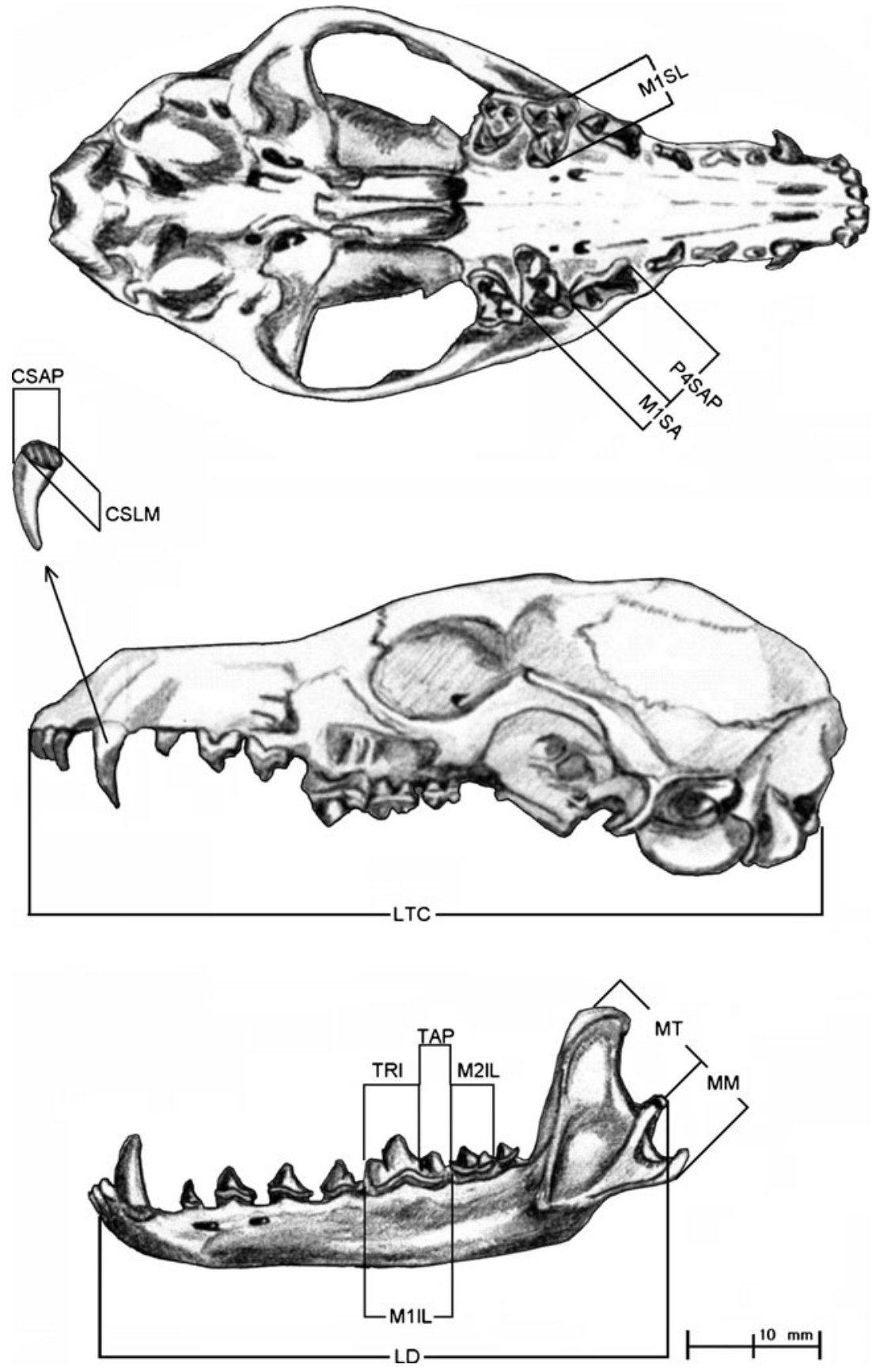

1980; Ricklefs and Miles 1994). Van Valkenburgh (1988, 1989), Van Valkenburgh and Koepfli (1993), and Van Valkenburgh and Wayne (1994) demonstrated that the utilization of morphological ratios (like those utilized in our study) instead of using raw measurements, provided a more direct description of the shape of trophic structures, although possible problems derived from allometries should be taken into account. We used these ratios to construct tridimensional graphics utilizing three of them as axes of the morphospace. In all the cases, we used C1L (relative length of the upper canine) as one of the axes of the morphospace.
C1L is correlated with the body weight of the carnivorans included in our study (Spearman rank correlation, $r=1$, $p<0.001$ ), adjusting in this way the effects of body size. The positions of the species in the morphospace are then assigned according to similarities and differences in the morphology of their trophic apparatus (Van Valkenburgh 1989; Márquez and Fariña 2003).

Finally, a Principal Components Analysis (PCA) was used to explore relations between ratios and to complement the information on the location of the species within the mophospaces defined by the ratios. 


\section{Dietary Analysis and Trophic Guild Identification}

To test the correspondence among morphoguilds and trophic guilds, we used diet information of carnivorans from Patagonia and trophic guild identification from our previous works (Zapata et al. 2007 and references therein). The diets of these species were estimated from fresh feces collected between July 1998 and August 2000 and corresponded to the two climatic seasons mentioned above. The importance of each prey type in the diet of each predator was quantified by the dry mass of each food type in the feces $\times 100 /$ total dry mass of feces, because we were not able to transform the dry weight of scats to consumed biomass for all the species. Fedriani and Travaini (2000) and Klare et al. (2011) recommended the use of the mass of diet components in the scats when no such transformation is available. With diet results, we first calculated diet overlap between species pairs by using a symmetrical overlap index (Pianka 1973). With diet overlap values we then constructed overlap matrices called "similarity matrices." We produced two similarity matrices, which corresponded to each climatic season (spring-summer and autumn-winter). We determined guild membership by entering the similarity matrices into the clustering technique unweighted pair-group method with arithmetic averaging (UPGMA, Sneath and Sokal 1973; Jaksic and Delibes 1987). To determine the level of similarity that defines the groups in the dendrogram (i.e., guilds), we used an objective method that allowed us to identify guilds with statistical significance (Jaksic and Medel 1990), based on bootstrap procedures. We used one of the randomization algorithms proposed by Lawlor (1980) to resample the predator by prey matrix (dietary matrix). This algorithm retained zero values (where they were found) of frequencies of dry weight of prey (rows), independently and simultaneously for each and every predator (columns) in the matrix. The dietary overlap between all pairs of predators was computed in every iteration obtaining overlap pseudovalues. We repeated this procedure 1,000 times to obtain a frequency distribution of pseudovalues, and that overlap pseudovalue that exceeded the $95 \%$ percentile was chosen as the cutoff point in the dendrogram (Jaksic and Medel 1990). Statistical analyses were performed with STATISTICA 6.0 and Microsoft Office Excel for PC

\section{Results}

\section{Morphoguilds Identification}

We selected the relative length of upper canine (C1L), lower first molar blade size relative to dentary length (M1BS), and relative upper grinding area (RUGA) as axes to generate the first morphospace because these last ratios indicate opposite functions, slicing and grinding. Accordingly, felids segregate from the rest of the carnivorans for presenting a great development of the blade size of their carnassials (Fig. 2a). In the opposite side of the morphospace, Conepatus was located, overlapping little with $L$. griseus, due to the great development of the grinding area of their lower molars, adapted for crushing resistant foods like arthropods and fruit. A gradient of carnivory-omnivory- insectivory/herbivory could be observed, with the canids and Galictis situated in the center of the morphospace. The smaller grinding areas of M1and M2, on one hand, and the greater blade length of M1 in the other, suggest that Galictis is the most carnivorous of the three species. In this morphospace, Puma and L. culpaeus are also separated from the rest of species due to the great development of their canines (highest values of C1L, Fig. 2a). When replacing M1BS by the relative blade length of lower first molar (RBL, Fig. 2b), the separation among these three groups is more evident. We excluded the felids from the morphospace (Fig. 2c and d), and Galictis occupied a position alone, while the positions of Conepatus and L. griseus overlapped due to the great development of the grinding area of post-carnassial molars (Fig. 2d). Galictis and L. culpaeus occupy independent positions although the fox is still in the center of the morphospace, and so it is considered more omnivorous than Galictis. In the morphospace constructed with the mechanical advantage of the temporalis muscle (MAT) and M1BS (Fig. 2e), L. griseus and Conepatus situated in one of the extremes, with little overlap with Galictis, Leopardus and L. culpaeus in the center and Puma alone, well separated from the rest of the species. Finally, the mechanical advantage of the masseter muscle (MAM) in relation to M1BS (Fig. 2f) separates Puma and Galictis in one side, and two groups with little overlap composed of Leopardus and L. culpaeus, and L. griseus and Conepatus, respectively.

Taking into account the relative positions of the six species in the morphospaces constructed with different combination of ratios, we identified four morphoguilds composed of: 1) Puma, who segregates from the rest of the species of the assemblage not only for its high degree of dental and mandibular specialization, but also for its great body size, which allows it to hunt and consume larger prey. 2) Leopardus with a specialized dental pattern for consuming flesh, and Galictis, whose location in the morphospace was closer to the felids, suggesting specialization in the consumption of flesh. 3) L. culpaeus, as expected for canids, possesses a generalized dental pattern for feeding on a great variety of foods, but it is heavier than L. griseus, and exhibits a major trend to carnivory. 4) Conepatus, specialized in the consumption of invertebrates or fruit, suggests trophic segregation from the rest of the species except $L$. griseus, with which it overlaps in the morphospace.

In the PCA, three components represented the $99.03 \%$ of total variation (Fig. 3). The higher values of variables contribution to each component were achieved by the relative 
a

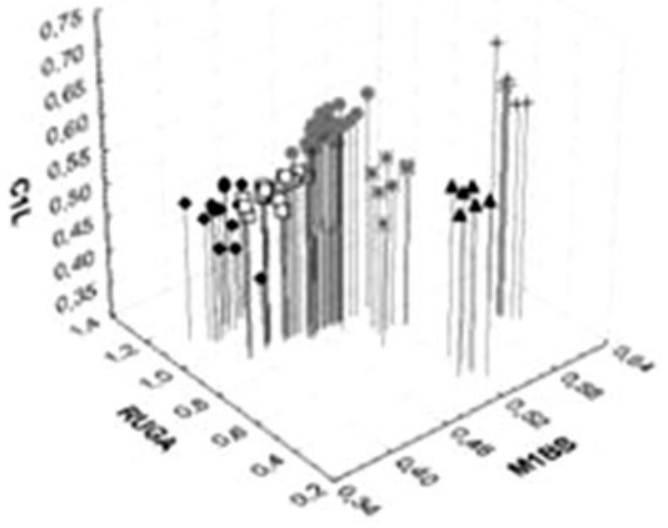

C

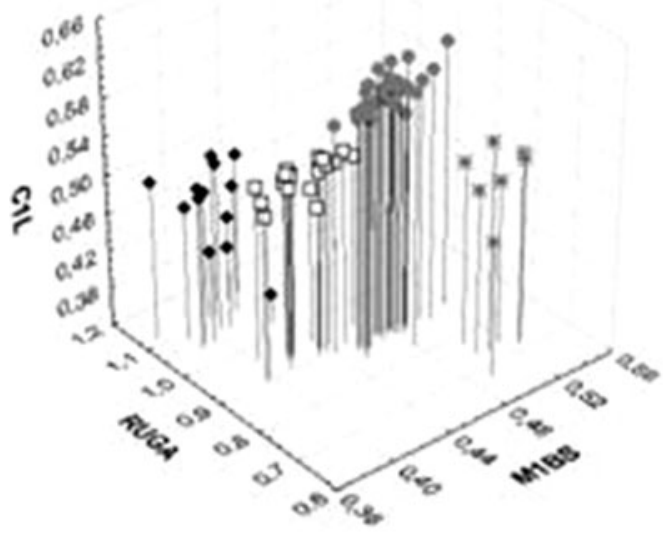

e

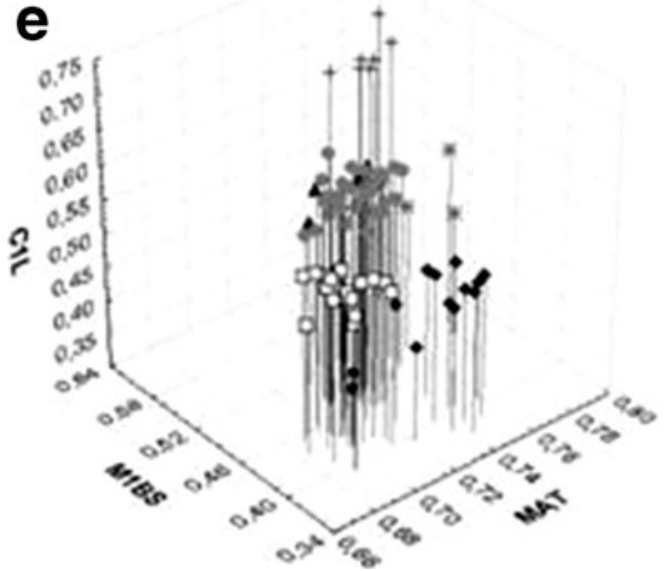

Fig. 2 Morphospaces derived from the use of the different ratios where the relative position of six $(\mathbf{a}, \mathbf{b}, \mathbf{e}, \mathbf{f})$ and four $(\mathbf{c}, \mathbf{d})$ species of carnivorans from Santa Cruz are shown. The definitions of the ratios are in the Materials and Methods. a, C1L, RUGA, M1BS; b, C1L,

grinding area of lower molars (RLGA), the relative size of the upper canines $(\mathrm{C} 1 \mathrm{~L})$, and the relative blade length of lower carnassial teeth (RBL) respectively. It can be seen b

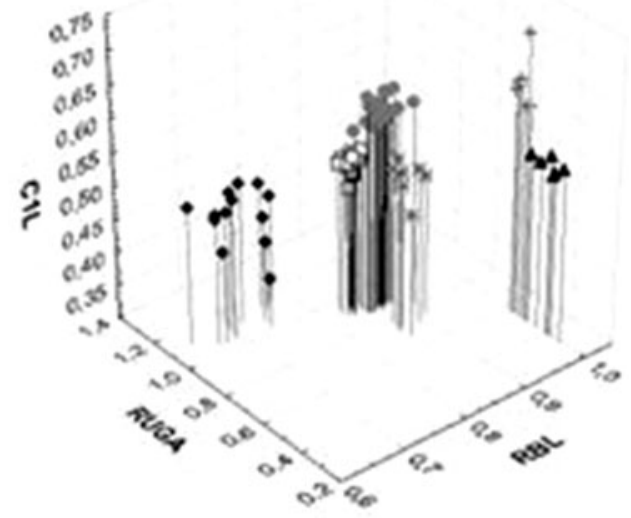

d
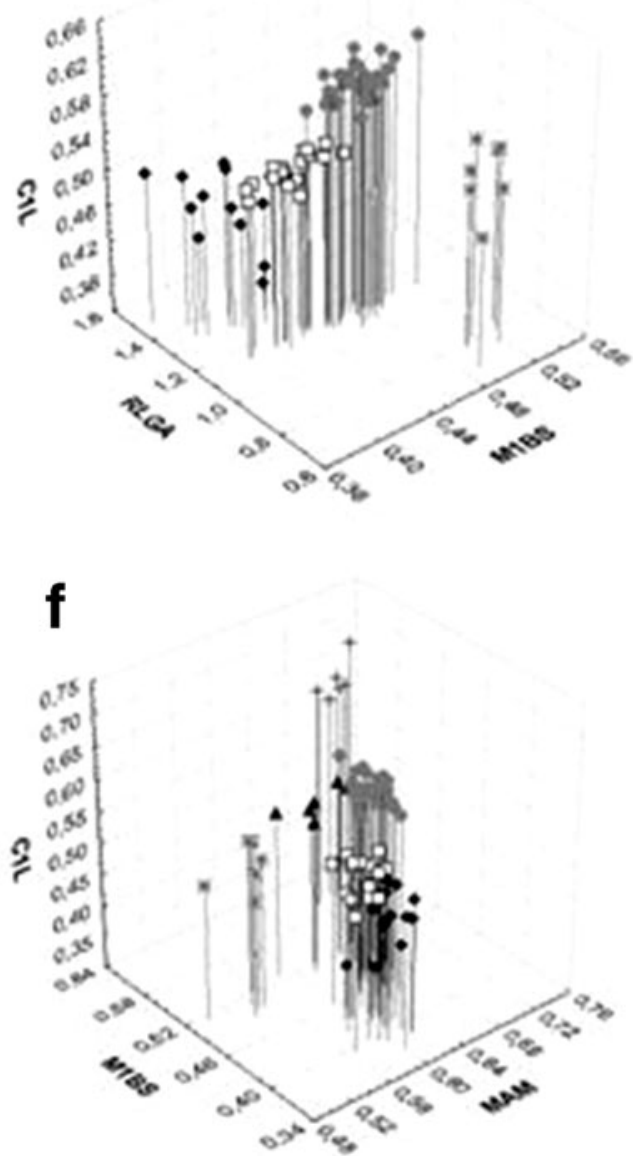

RUGA, RBL; c, same as a without felids; d, C1L, RLGA, M1BS (felids excluded); e, C1L, M1BS, MAT; f, C1L, M1Bs, MAM. Modified from Zapata et al. (2008)

from the figure that the six predator species were separated into four groups that match those identified by our ecomorphological analysis. 


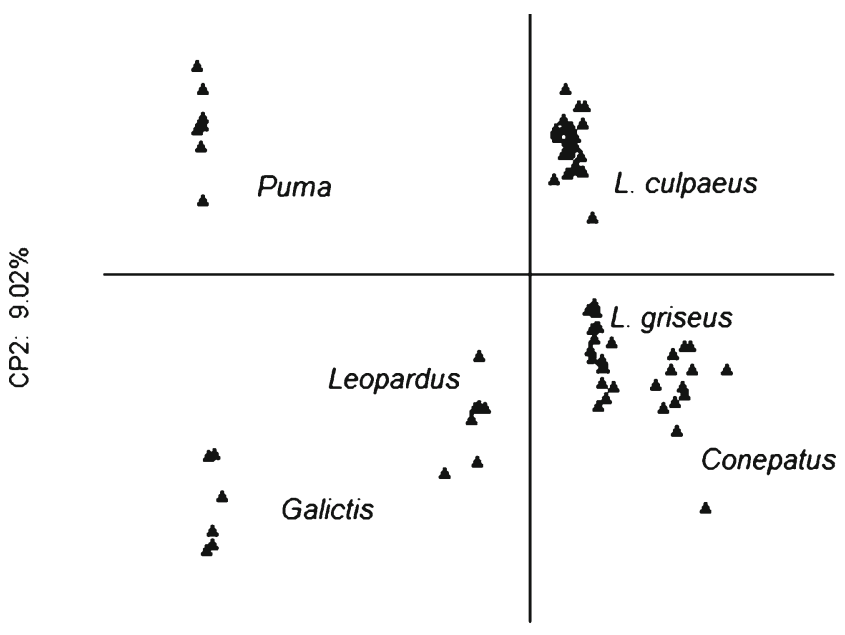

CP1: $87.98 \%$

Fig. 3 Principal Component 1 versus Principal Component 2 obtained after a Principal Components Analysis performed on the six species of carnivorans from Santa Cruz, using all ratios

\section{Guild Structure of Carnivoran Assemblage}

During the autumn winter period, the carnivorans were separated into four trophic guilds that contained species that exploit resources in a similar way. The cutoff point was achieved at a similarity level of $54 \%(p<0.05)$. The guilds were named according to the dominant prey consumed by their members. Three guilds were composed by only one species and one guild was composed by three species (Fig. 4a); they were: Guild I: "xenarthrans-ungulates" feeding guild composed by Puma, a large felid that ate mainly xenarthrans (Patagonian pichi, Zaedyus pichii) and big rodents (the mara, Dolichotis patagonum), and is capable of subduing ungulates larger than itself, like the guanaco (Lama guanicoe). Also the introduced European hare (Lepus europaeus) was abundant in the diet of this felid. Guild II: "rodents" feeding guild, composed by Leopardus, a small cat that consumed mainly rodent species over the year, rabbit rats (Reithrodon auritus), and Magellan's tucos (Ctenomys magellanicus). Guild III: "lagomorphs" feeding guild, composed by Galictis and the two canids (L. culpaeus and L. griseus). Galictis behaved as a specialist in the consumption of mammals; its diet was dominated by rodents (lesser cavies, Microcavia australis, and rabbit rats were the more abundant species), but also consumed European hare in a great proportion. European hare was the most important item together with large rodents (mainly lesser cavies and rabbit rats), in the diet of $L$. culpaeus. A great variety of foods were included in the diet of the grey fox during this period, but rodents, European hares, and xenarthrans were the more important items. The three species converged in the consumption of European hares and lesser cavies during this period. Note that Galictis and L. culpaeus constituted a subunit inside the group (Fig. 4a), because they consumed hares in a greater proportion than L. griseus . Though lesser cavies, a rodent species, were an important item in the diet of these predators, we named this guild as the "lagomorphs" feeding guild to make a difference with the previous guild. Guild IV: "arthropods" feeding guild, composed by Conepatus. This species ate a great proportion of arthropods during this season, though rodents, carrion, birds, and fruits were also present in its diet.

During the spring-summer, the same guilds were present, but with some variation in species composition. Puma, Leopardus, L. culpaeus, and Conepatus stayed in the same guilds but the Galictis overlapped with Leopardus (Fig. 4b), because this species increased the consumption of rodents and decreased the consumption of lagomorphs. On the other hand, L. griseus increased the consumption of arthropods, overlapping its diet with that of Conepatus (Fig. 4b).

Correspondence Between Morphoguilds and Trophic Guilds

Although the six species were assigned to four guilds in both spaces, the species composition of both trophic and morphological guilds was coincident only during the spring-summer. In autumn-winter, Galictis and L. griseus, which were formerly in the rodents and arthropods feeding guilds respectively, clustered together with L. culpaeus in the lagomorphs feeding guild, and therefore there was no coincidence of species in both trophic and morphological spaces.
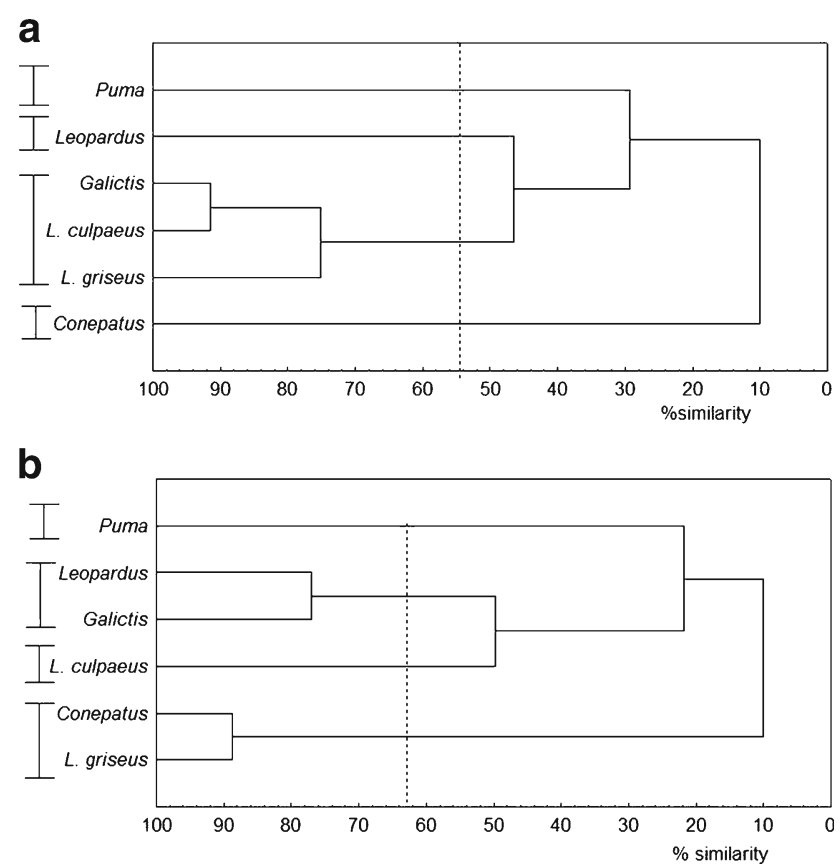

Fig. 4 Trophic guild structure of carnivoran assemblage from NE Santa Cruz, Argentine Patagonia during a, autumn-winter and $\mathbf{b}$, springsummer. Dotted lines at $54 \%$ and $63 \%$ (a and $\mathbf{b}$, respectively) of similarity indicate the existence of four guilds (in brackets) with statistical significance $(p<0.05)$. From Zapata et al. (2007) 


\section{Discussion}

Ecomorphological studies suggest that the distribution of ecomorphs in mammalian predators assemblages of great body size is predictive, independent of where or when they have existed. Each assemblage contains generalist ecomorphs (foxes, civets, chacals) in the center of the morphospace. Separated from this central group and leaving spaces among them, there are another three groups: specialists in consuming flesh (felids), specialists in consuming bones and flesh (hyenids), and weakly carnivorous species (ursids). Only the central group includes more than one family of the Order Carnivora (Van Valkenburgh 1995). This pattern of dispersion of species is iterative in the course of evolution, despite the significant differences in the phylogenetic composition of species, although hyenids and ursids ecomorphs may be absent (Van Valkenburgh 1988, 2007; Palmqvist et al. 1999; Purvis et al. 2001; Prevosti and Martin in press). These studies also suggest that the pattern of resource partitioning among sympatric carnivorans remained stables for millions of years and probably reflected interspecific competition and aspects of trophic resources (Van Valkenburgh 1995, 2007). Moreover, ecomorphological studies in carnivorans have focused on species weighting more than $7 \mathrm{~kg}$ (but see Friscia et al. 2007 and references therein), because it is supposed that interspecific competition for resources would be stronger among them. Likewise, smaller predator species, like the carnivorans of our study, may be potential competitors, if they overlap in resources use (Keddy 2001) and if these are limited (Wiens 1989). In our study, carnivorans were separated into four morphoguilds. Felids, specialists in the consumption of flesh, were located in one extreme of the morphospace; mephitids, specialists in the consumption of non-vertebrate prey and fruit in the opposite side. The rest of the species were located in the center of the morphospaces, but Galictis was located closer to Leopardus, forming the same guild; and P. griseus closer to Conepatus, forming another guild.

Our objective was to evaluate the correspondence among the relative positions of predators in ecological and morphological spaces. We predicted that ecological guilds should be more flexible than morphoguilds, as demonstrated by the results. Although the six species were assigned to four guilds in both spaces, the species composition of both trophic and morphologic guilds was coincident only during one of the studied periods. The most obvious explanation is based on the assumption that species can change from one guild to another in ecological time (Farías and Jaksic 2006) while the relative positions of species in the morphospace will be fixed. Obviously, the abundance and availability of prey impose ecological restrictions to predators and to the competitive interactions among them. Arid and semiarid environments like Patagonia are notorious for the fluctuation of trophic resources, which affect the ecology of the resident species
(Korpimäki 1984; Wiens 1993; Jiménez et al. 1992; Meserve et al. 1995; Holmgren et al. 2006). In these environments, species with trophic plasticity, like L. griseus (Zapata et al. 2005a), may change from one guild to another, which is coherent with its generalized dental patterns, highlighting an adequate function of its trophic apparatus. Moreover, $L$. griseus is subjected to intraguild competition (sensu Polis et al. 1989) by dominant L. culpaeus. In southern Patagonia, L. griseus reduces the risk of predation by L. culpaeus by avoiding its encounter (Johnson and Franklin 1994a, b; Jiménez et al. 1996; Zapata et al. 2005a). According to these authors, although both species are able to consume the same type of prey, L. culpaeus monopolizes those areas with more profitable prey to meet the energy demands of its large body size, and excludes the small L. griseus to areas where resources are, from an energetic point of view, less profitable (Novaro et al. 2004; Zapata et al. 2005a). Likewise, dramatic responses of vertebrate predators to fluctuations in the density of their prey are well known in different parts of the world (Andersson and Erlinge 1977; O’Donoghue et al. 1977, 1998a, b; Redpath and Thirgood 1999; Fuller and Sievert 2001). For example, after a collapse in the abundance of rabbits in Doñana National Park, southern Spain, the red fox (Vulpes vulpes), compensated for the scarcity of rabbits (although rabbits were not an important prey in its diet) by increasing the consumption of carrion and birds, and changed from the insects-fruits feeding guild to the birds, reptiles, and carrion feeding guild (Zapata et al. 2007; Ferreras et al. 2011). Also, diet specialists can change from feeding guild, if their preferred prey is scarce. In our study, Galictis, a small mustelid specialized in the consumption of mammals in Patagonia (Delibes et al. 2003; Zapata et al. 2005b), was capable of subduing introduced adult hares, which weight in average $3 \mathrm{k}$ in our study area, and changed to the lagomorphs feeding guild when rodents were scarce (Zapata et al. 2005b), overlapping with the foxes. The coherence between the morphology of its trophic apparatus and its diet would indicate an adequate function enhancing a successful trophic strategy.

Morphological specialization toward some type of diet has been corroborated repeatedly, and there are no doubts that the relationship exists. However, the inference of interactions between species of the past from its morphology must be considered with caution, as should also be predictions about morphology derived from short-term ecological studies. Our work suggests that there is not a total correspondence between morphoguilds and trophic guilds, at least in our assemblage and in the temporal scale utilized. While species occupy discrete clusters in morphospaces, the same species may occupy different places in ecological space. Nevertheless, we believe that this correspondence could be achieved with long-term studies in persistent assemblages, those in which guild structures and members composition are stable over time. 
Finally, we are aware that our morphoguilds identification may be questioned, because species from different families were assigned to the same morphoguild. Morphology of related species could be affected by phylogeny, because it is expected for closely related species to be morphologically similar regardless of their diet (Ricklefs and Miles 1994; Palmqvist et al. 1999; Popowics 2003). Friscia et al. (2007) have shown that among small carnivorans, canids tend to be phylogenetically constrained. According to these authors, canids are nearly all carnivores, except the more omnivorous raccoon dog (Nyctereutes procyonoides). This species always groups with the other canids when discriminant function analysis (DFA) was performed on morphological variables, despite its distinct diet (Friscia et al. 2007). The mustelids display more varied diets across the family, but still tend to group together in some analyses, implying a phylogenetic constraint on their morphology (Friscia et al. 2007). Nevertheless, it may occur that the morphological differences among species deviate from what is expected from phylogeny. In our study, L. griseus differs from its closest relative, L. culpaeus (Wayne et al. 1989), because of the emphasis in the development of grinding areas of its lower molars and both were assigned to different morphoguilds.

Acknowledgments Financial support was provided by the Universidad Nacional de la Patagonia Austral (UNPA PI/29/B081, 050, 013, 124), Consejo Nacional de Investigaciones Científicas y Técnicas (CONICETPEI-6065). The Secretaría de Agricultura, Ganadería y Pesca de la Nación (SAGPyA Nos. 613/96, 716/97 and 925/97), the Secretaría de Medio Ambiente y Desarrollo Humano, and the Consejo Agrario Provincial Emilio Daher, Miguel Santillán, Martín Yaya and Mara Brossman, Rolando Martínez Peck assisted during field work. We thank the Administración de Parques Nacionales for authorizing us to work inside the protected area (MNBP). Special thanks to Javier Pereira and Francisco Prevosti for inviting us to participate in the Symposium "Structure of the carnivore communities of South America: present and past" during the "II Latin-American Congress of Mastozoology," Buenos Aires, November of 2012. Two anonymous reviewers greatly improved our manuscript with their suggestions, our thanks to both of them.

\section{Appendix 1}

Description of the ratios used in this study, after Radinsky (1981), Van Valkenburgh (1989), and Van Valkenburgh and Koepfli (1993). Illustrations of the measurements are in Fig. 1.

RBL: Relative blade length of lower first molar $\left(\mathrm{M}_{1}\right.$ carnassial), measured as the ratio of trigonid length to total anteroposterior length of $\mathrm{M}_{1}$ (TRI/M1L)

RLGA: Relative lower grinding area, measured as the square root of the summed areas of the $\mathrm{M}_{1}$ talonid and $\mathrm{M}_{2}$ (if present) divided by the length of the $\mathrm{M}_{1}$ trigonid. Area was estimated as the product of maximum width and length of the talonid of $\mathrm{M}_{1}$ and $\mathrm{M}_{2}$, respectively $\left((\mathrm{TAP} \times \mathrm{TLM})+\left(\mathrm{M}_{2} \mathrm{~L} \times\right.\right.$ $\left.\left.\mathrm{M}_{2} \mathrm{~A}\right)\right) 1 / 2 / \mathrm{TRI}$.
RUGA: Relative upper grinding area, measured as the square root of the summed areas of $\mathrm{M}_{1}$ and $\mathrm{M}_{2}$ (if present) divided by the anteroposterior length of $\mathrm{P}^{4}$ (upper carnassial). Area was estimated by the product of width and length of $\mathrm{M}_{1}$ and $\mathrm{M}_{2}$, respectively $\left(\mathrm{MS}_{1} \mathrm{~L} \times \mathrm{MS}_{1} \mathrm{~A}\right) 1 / 2 / \mathrm{P}^{4} \mathrm{SAP}$.

M1BS: $M_{1}$ blade size relative to dentary length, measured as the length of the trigonid of $\mathrm{m} 1$ (carnassial) divided by dentary length (TRI/LD).

MAT: Mechanical advantage of the temporalis muscle, measured as the distance from the mandibular condyle to the apex of the coronoid process divided by dentary length (MT/LD)

MAM: Mechanical advantage of the masseter muscle, measured as the distance from the mandibular condyle to the ventral border of the mandibular angle divided by dentary length (MM/LD)

C1: Relative size of the upper canine, measured by the square root of the basal area of $\mathrm{C}^{1}$ measured as the product of the maximum antero-posterior length of $\mathrm{C}^{1}$ and the maximum medium-lateral length of $\mathrm{C}^{1}$ (CSAP $\mathrm{x}$ CSML) $1 / 2$

C1L: Relative length of upper canine, measured by the máximum length of $\mathrm{C}^{1}$ divided by the total skull length (CSLM/LTC).

\section{References}

Andersson M, Erlinge S (1977) Influence of predation on rodent populations. Oikos 29:591-597

Biknevicius AR, Van Valkenburgh B (1996) Design for killing: craniodental adaptations of predators. In: Gittleman JL (ed) Carnivore Behavior, Ecology and Evolution, Vol. 2. Cornell University Press, Ithaca, pp 428-393

Blondel J (2003) Guilds of functional groups: does it matters? Oikos 100:223-232

Davies TJ, Meiri S, Barraclough TG, Gittleman JL (2007) Species coexistence and character divergence across carnivores. Ecol Letters 10:146-152

Dayan T, Simberloff D (2005) Ecological and community-wide character displacement: the next generation. Ecol Letters 8:875-894

Delibes MA, Travaini A, Zapata S, Palomares F (2003) Alien mammals and the trophic position of the lesser grison (Galictis cuja) in Argentinean Patagonia. Can J Zool 81:157-162

Emerson SB, Radinsky LB (1980) Functional analysis of sabertooth cranial morphology. Biol J Linn Soc 15:369-368

Ewer RF (1973) The Carnivores. Cornell University Press, Ithaca

Farías A, Jaksic FM (2006) Assessing the relative contribution of functional divergence and guild aggregation to overall functional structure of species assemblages. Ecol Informatics 4: $367-375$

Fedriani JM, Travaini A (2000) Predator trophic guild assignment: the importance of the method of diet quantification. Rev Ecol - La Terre et la Vie 55:129-139

Ferreras P, Travaini A, Zapata SC, Delibes M (2011) Short-term responses of mammalian carnivores to a sudden collapse of rabbits in Mediterranean Spain. Basic Appl Ecol 12:116-124 
Figueirido B, Soibelzon L (2009) Inferring palaeoecology in extinct tremarctine bears (carnivora, ursidae) using geometric morphometrics. Lethaia 43:209-222

Friscia R, Van Valkenburgh B, Biknevicius AR (2007) An ecomorphological analysis of extant small carnivorans. J Zool 272:82-100

Fuller TK, Sievert PR (2001) Carnivore demography and the consequences of changes in prey availability. In: Gittleman JL, Funk SM, Macdonald D, Wayne RK (eds) Carnivore Conservation. Cambridge University Press, Cambridge, pp 163-178

García N, Virgós E (2007) Evolution of community composition in several carnivore palaeoguilds from the European Pleistocene: the role of interspecific competition. Lethaia 40:33-44

Hertel F (1994) Diversity in body size and feeding morphology within past and present vulture assemblages. Ecology 75:1074-1084

Holmgren M, Stapp P, Dickman CR, Gracia C, Graham S, Gutiérrez JR, Hice C, Jaksic F, Kelt DA, Letnic M, Lima M, López BC, Meserve PL, Milstead WB, Polis GA, Previtali MA, Ritcher M, Sabaté S, Squeo FA (2006) Extreme climatic events shape arid and semiarid ecosystems. Front Ecol Environ 4:87-95

Jaksic F, Delibes M (1987) A comparative analysis of food-niche relationships and trophic guild structure in two assemblages of vertebrate predator differing in species richness: causes, correlations, and consequences. Oecologia 71:461-472

Jaksic FM, Medel RG (1990) Objective recognition of guilds: testing for statistically significant species clusters. Oecologia 82:87-92

Jiménez JE, Feisinger P, Jaksic F (1992) Spatiotemporal patterns of an irruption and decline of small mammals in northcentral Chile. J Mammal 73:356-364

Jiménez JE, Yáñez JL, Tabilo EL, Jaksic FM (1996) Niche complementarity of South American foxes: reanalysis and test of a hypothesis. Rev Chilena Hist Nat 69:113-123

Johnson WE, Franklin WL (1994a) Role of body size in the diets of sympatric gray and culpeo foxes. J Mammal 75:163-174

Johnson WE, Franklin WL (1994b) Spatial resource partitioning by sympatric gray fox (Dusicyon griseus) and culpeo fox (Dusicyon culpaeus) in southern Chile. Can J Zool 72:1788-1793

Klare U, Kamler JF, Macdonald DW (2011) A comparison and critique of different scat-analysis methods for determining carnivore diet. Mammal Rev 41:294-312

Keddy PA (2001) Competition. Kluwer Academic Publisher, Norwell

Korpimäki E (1984) Population dynamics of birds of prey in relation to fluctuations in small mammals populations in western Finland. Ann Zool Fennici 21:287-293

Lawlor LR (1980) Structure and stability in natural and randomly constructed competitive communities. Am Naturalist 116:394-408

León RJC, Bran D, Collantes M, Paruelo JM, Soriano A (1998) Grandes unidades de vegetación de la Patagonia Extra Andina. Ecol Austral $8: 125-144$

Márquez A, Fariña RA (2003) Dental morphology and diet in canids and procyonids from Uruguay. Mammalia 67:567-573

Meloro C (2011) Morphological disparity in Plio-Pleitocene large carnivore guilds from Italian peninsula. Acta Paleontol Pol $56: 33-44$

Meserve PL, Gutierrez JR, Contreras LC, Jaksic FM (1995) Heterogeneous responses of small mammals to an El Niño Southern Oscillation event in north-central semiarid Chile and the importance of ecological scale. J Mammal 76:580-595

Novaro A, Funes MC, Jiménez J (2004) Patagonian foxes. In: Macdonald D, Sillero-Zubiri C (eds) Biology and Conservation of Wild Canids. Oxford University Press, Oxford, pp 243-254

O’Donoghue M, Boutin S, Krebs CJ, Hofer EJ (1977) Numerical responses of coyotes and lynx to the snowshoe hare cycle. Oikos $80: 150-162$

O'Donoghue M, Boutin S, Krebs CJ, Murray DL, Hofer EJ (1998a) Behavioural response of coyotes and lynx to the snowshoe hare cycle. Oikos 82:169-183
O'Donoghue M, Boutin S, Krebs CJ, Zuleta G, Murray DL, Hofer EJ (1998b) Functional responses of coyotes and lynx to the snowshoe hare cycle. Ecology 79:1192-1208

Palmqvist P, Arribas A, Martínez-Navarro B (1999) Ecomorphological study of large canids from the lower Pleistocene of southeastern Spain. Lethaia 32:75-88

Pianka ER (1973) The structure of lizard communities. Annu Rev Ecol Syst 4:53-74

Polis GA, Myers CA, Holt RD (1989) The ecology and evolution of intraguild predation: potential competitors that eat each other. Annu Rev Ecol Syst 20:297-330

Popowics TE (2003) Postcanine dental form in the Mustelidae and Viverridae (Carnivora: Mammalia). J Morphol 256:322-341

Prevosti FJ, Palmqvist P (2001) Analisis ecomorfologico del canido hipercarnivoro theriodictis platensis (mammalia carnívora) del pleistoceno de Sudamerica. Ameghiniana 38:375-384

Prevosti FJ, Vizcaíno SF (2006) Paleoecology of the large carnivore guild from the late pleistocene of Argentina. Acta Paleontol Pol 51:407422

Prevosti FJ, Martin FM (2013) Paleoecology of the mammalian predator guild of Southern Patagonia during the latest Pleistocene: ecomorphology, stable isotopes, and taphonomy. Quatern Int 305:74-84

Purvis A, Mace GM, Gittleman JL (2001) Past and future carnivore extinctions: a phylogenetic perspective. In: Gittleman JL, Funk SM, Macdonald D, Wayne RK (eds) Carnivore Conservation. Cambridge University Press, Cambridge, pp 11-34

Radinsky LB (1981) Evolution of skull shape in carnivores. 1. Representative modern carnivores. Paleobiology 6:295-312

Radinsky LB (1985) Aproaches in evolutionary morphology: a search for patterns. Annu Rev Ecol Syst 16:1-14

Redpath S, Thirgood SJ (1999) Numerical and functional responses in generalist predators: hen harriers and peregrines on Scottish grouse moors. J Animal Ecol 68:879-892

Ricklefs RE, Miles DB (1994) Ecological and evolutionary inferences from morphology: an ecological perspective. In: Wainwright PC, Reilly SM (eds) Ecological Morphology. Integrative Organismal Biology. The University of Chicago Press, Chicago and London, pp 13-41

Ricklefs RE, Travis J (1980) A morphological approach to the study of avian community organization. Auk 97:321-338

Root RB (1967) The niche exploitation pattern of the blue-gray Gnatcatcher. Ecol Monogr 37:317-350

Sneath PHA, Sokal R (1973) Numerical Taxonomy. The Principle and Practice of Numerical Classification. W.H. Freeman \& Co, San Francisco

Van Valkenburgh B (1988) Trophic diversity in past and present guilds of large predatory mammals. Paleobiology 14:155-173

Van Valkenburgh B (1989) Carnivore dental adaptations and diet: a study of trophic diversity within guilds. In: Gittleman JL (ed) Carnivore Behavior, Ecology and Evolution. Cornell University Press, Ithaca, pp 410-436

Van Valkenburgh B (1995) Tracking ecology over geological time: evolution within guilds of vertebrates. Evolution 2:71-76

Van Valkenburgh B (2007) Déjà vu: the evolution of feeding morphologies in the Carnivora. Integr Comp Biol 47:147-163

Van Valkenburgh B, Koepfli KP (1993) Cranial and dental adaptations to predation in canids. Symp Zool Soc Lond 65:15-37

Van Valkenburgh B,Wayne RK (1994) Shape divergence associated with size convergence in sympatric East African jackals. Ecology 75:1567-1581

Wainwright PC, Reilly SM (Eds) (1994). Ecological Morphology. University of Chicago Press, Chicago and London

Wayne RK, Van Valkenburgh B, Kat PW, Fuller TK, Johnson W, O’Brien SJ (1989) Genetic and morphological divergence among sympatric canids. J Hered 80:447-454 
Wiens JA (1989) The Ecology of Bird Communities. Vol 2. Processes and Variations. Cambridge University Press, Cambridge.

Wiens JA (1993) Fat times, lean times and competition among predators. Trends Ecol Syst 8: 348-349

Zapata SC, Funes MC, Novaro AJ (1997a) Estimación de la edad en el zorro colorado patagónico (Pseudalopex culpaeus). Mastozool Neotrop 4:145-150

Zapata SC, García Perea R, Beltrán JF, Ferreras P, Delibes M (1997b). Age determination of Iberian Lynx (Lynx pardinus) using canine radiograph and cementum annuli enumeration. Z Säugetierk 62:119-123

Zapata SC, Travaini A, Delibes M (1995) Comparación entre varias técnicas de estimación de la edad en zorros, Vulpes vulpes, de Doñana (sur de la península Ibérica). Doñana, Acta Verteb 22:29-50
Zapata SC, Travaini A, Delibes M, Martínez Peck R (2005a) Food habits and resource partition between grey and culpeo foxes in southeastern Argentine Patagonia. Stud Neotrop Fauna Environ 40:97-103

Zapata SC, Travaini A, Delibes M, Martínez Peck R (2005b) Annual food habits of the lesser grison (Galictis cuja) at the southern limits of its range. Mammalia 69:85-88

Zapata SC, Travaini A, Delibes M, Martínez Peck R (2008) Identificación de morfogremios como aproximación al reparto de recursos en ensambles de carnívoros terrestres. Mastozool Neotrop 15:85-101

Zapata SC, Travaini A, Ferreras P, Delibes M (2007) Analysis of trophic structure of two carnivore assemblages by means of guild identification. Europ J Wildl Res 53:276-286 